\title{
"Who infects Whom" - Reconstructing infection chains of Mycobacterium avium ssp. paratuberculosis in an endemically infected dairy herd by use of genomic data (Nigsch et al., 2021)
}

Supporting information S2 Fig.

A Shedding level
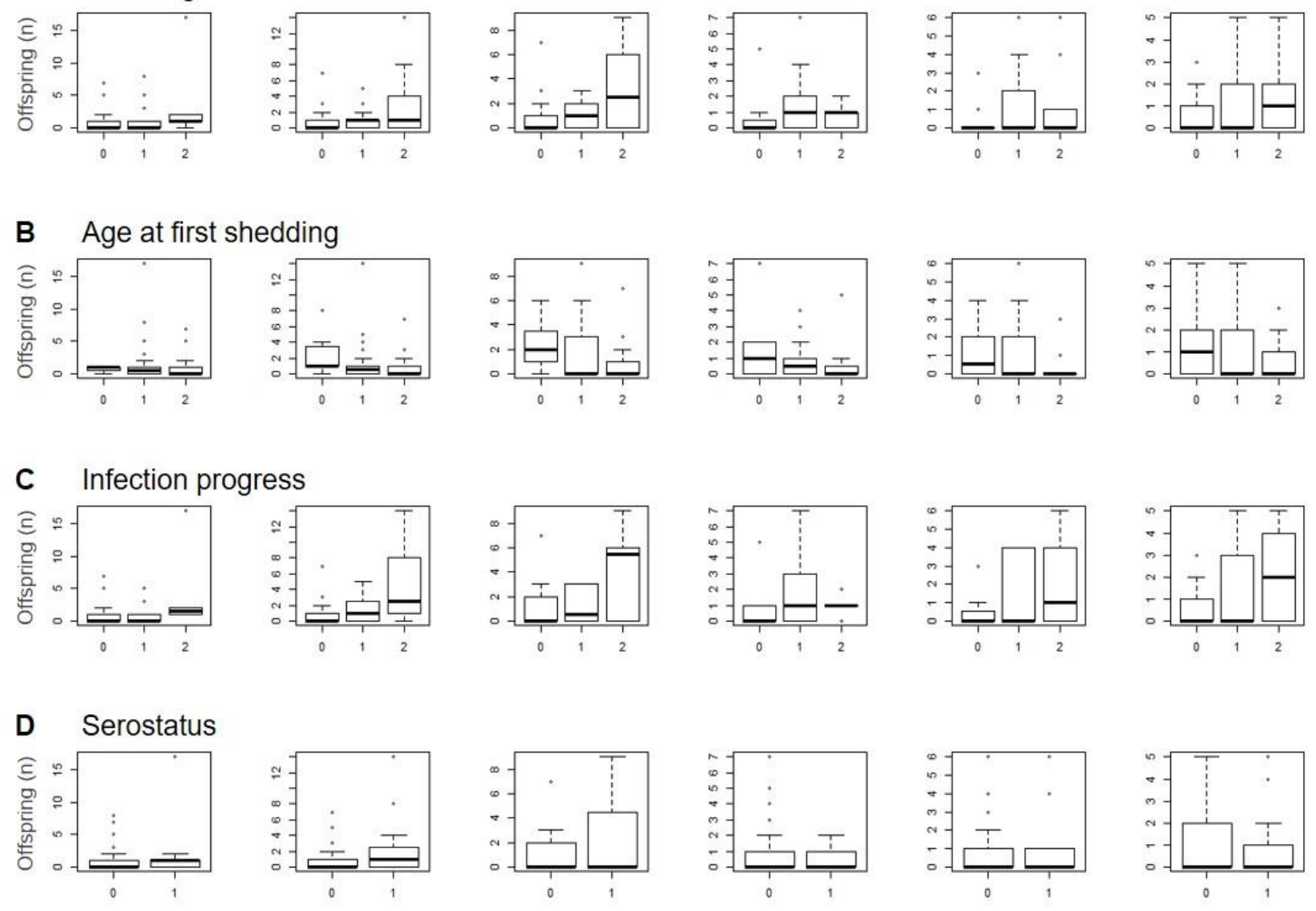

birth_Basic

birth_E

birth_S

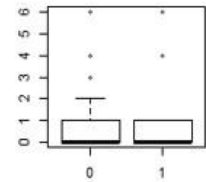

shed_E

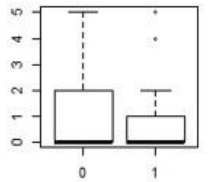

shed_S

S2 Fig. Numbers of recipients produced by individual cows. Boxplots with numbers of recipients produced by individual cows, by disease phenotype and scenario. (A) shedding level $(0-$ always faecal culture negative, 1 - low, 2 - high), (B) age at first shedding ( 0 - $\leq 3$ years, 1 - >3 years, 2 - ante mortem negative), (C) infection progress (0 - ante mortem negative, 1 - non-progressor, 2 progressor), (D) serostatus (0 - ELISA-negative, 1 - ELISA-positive). Scenarios (from left-most to rightmost column): [birth_Basic], [birth_E], [birth_S], [shed_Basic], [shed_E] and [shed_S]. 